\title{
Comparison of hormonal receptor and HER-2 status between breast primary tumours and relapsing tumours: clinical implications of progesterone receptor loss
}

\author{
Giuseppe Bogina • Laura Bortesi • Marcella Marconi • Marco Venturini • \\ Gianluigi Lunardi • Francesca Coati - Alberto Massocco • Erminia Manfrin • \\ Cristina Pegoraro • Giuseppe Zamboni
}

Received: 31 March 2011 /Revised: 20 May 2011 / Accepted: 23 May 2011 /Published online: 4 June 2011

(C) The Author(s) 2011. This article is published with open access at Springerlink.com

\begin{abstract}
Differences in hormone receptor and HER-2 status between primary tumour and corresponding relapse could have a substantial impact on clinical management of patients. The aim of this study was to evaluate change in expression of hormone receptors and HER-2 status between primary tumour and corresponding local recurrence or distant metastasis. We analysed 140 primary tumours and related recurrent or metastatic samples. Hormone receptors status was evaluated by immunohistochemistry, while HER2 status by immunohistochemistry and silver in situ hybridisation. A change in HER-2 was rare; $3.7 \%$ of cases by immunohistochemistry and only $0.7 \%$ by silver in situ hybridisation analysis. A change in estrogen and proges-
\end{abstract}

G. Bogina $\cdot$ L. Bortesi $\cdot$ M. Marconi $\cdot$ G. Zamboni

Department of Pathology, Sacro Cuore Hospital of Negrar,

Verona, Italy

M. Venturini $\cdot$ G. Lunardi $\cdot$ F. Coati

Department of Oncology, Sacro Cuore Hospital of Negrar,

Verona, Italy

\author{
A. Massocco \\ Department of Surgery, Sacro Cuore Hospital of Negrar, \\ Verona, Italy \\ E. Manfrin \\ Department of Pathology, University of Verona, \\ Verona, Italy \\ C. Pegoraro \\ Department of Oncology, Montecchio, \\ Vicenza, Italy \\ G. Bogina $(\square)$ \\ Istituto di Anatomia Patologica, Ospedale Sacro Cuore, \\ Via Don A Sempreboni 5, Negrar, \\ 37024 Verona, Italy \\ e-mail: giuseppe.bogina@sacrocuore.it
}

terone receptors was seen in $6.4 \%$ and $21.4 \%$ of cases, respectively. Estrogen receptor change was not affected by adjuvant therapy, whereas progesterone receptor was influenced by adjuvant chemotherapy associated to hormone therapy $(P=0.0005)$. A change in progesterone receptor was more frequent in distant metastases than in local recurrences $(P=0.03)$. In the setting of estrogen receptor positive tumours, patients with progesterone receptor loss in local recurrence had a statistically significant lower median metastasis free survival compared to others patients; progesterone receptor positive, 112 months; progesterone receptor negative, 24 months $(P=0.005)$. A change between primary tumour and corresponding relapse is frequent for progesterone receptor, infrequent for estrogen receptor and rare for HER-2. In cases with changes in HER-2, it is worthwhile reassessing HER-2 status with both immunohistochemistry and in situ hybridisation analysis. Progesterone receptor loss seems to be influenced by therapy and to correlate with a worse prognosis.

Keywords Breast carcinoma $\cdot$ HER- 2 Hormone receptor . Metastasis

\section{Introduction}

Hormone receptor and HER-2 status are the most important predictive markers in breast cancer. Their assessment is generally performed on resected primary tumour (PT) in order to select patients eligible for hormone and HER-2 directed therapies [1-7]. Most of the tumours that do respond initially to targeted therapies will gain acquired resistance [8]. Differences in hormone receptor and HER-2 status between PT and corresponding relapse could help to 
explain this acquired resistance and have a substantial impact on clinical management of these patients. Nevertheless, the results reported in different studies, concerning expression of biomarkers in PT and corresponding metastasis, are not homogeneous (Table 1) [1-30]. There are many hypotheses that could explain biomarkers change between PT and corresponding metastasis: clonal selection for hormone receptor and HER-2 during tumour progression due to intratumoral heterogeneity and/or to selective pressure from therapy; independent evolution of an early stem cell clone in both sites, instead of a linear progression from the PT to metastasis; false shifts related to detection and evaluation including tissue processing, reagent variability, type of test and scoring interpretation $[1,2,8,14$, $18,22,26,31]$. The aim of this study was to compare the expression of estrogen receptor (ER), progesterone receptor
(PR) and HER-2 status between PT and corresponding local recurrence (LR) or distant metastasis (DM) to evaluate whether therapy can modify this status and whether biomarkers change can affect prognosis.

\section{Materials and methods}

For this study, we considered all consecutive breast cancer DM and LR diagnosed at the Institute of Pathology of Sacro Cuore Hospital, Negrar, Verona between January 1998 and December 2009. There were 198 patients with histological samples of breast LR or DM. For 140 of these patients, the corresponding PT samples were retrieved from the files of the Institute of Pathology. For the remaining 58 cases, corresponding PT samples were not available. Cases

Table 1 Literature review of ER, PR and HER-2 discordance between primary tumours and corresponding metastatic sites

\begin{tabular}{|c|c|c|c|c|c|c|}
\hline & Cases & Metastatic sites & Type of analysis & ER $(\%)$ & PR (\%) & HER-2 (\%) \\
\hline Andersen 1988 [10] & 143 & ALM/DM & Biomarkers reassessment & 10 & & \\
\hline Li 1994 [17] & 83 & $\mathrm{LR} / \mathrm{DM}$ & Biomarkers reassessment & 29 & 44 & \\
\hline Van Agthoven 1995 [28] & 26 & ALM & Biomarkers reassessment & 0 & & \\
\hline Johnston 1995 [8] & 34 & LR & Biomarkers reassessment & 23 & 26 & \\
\hline Kuukasjarvi 1996 [16] & 50 & LR & Biomarkers reassessment & 24 & 24 & \\
\hline Shimizu 2000 [24] & 21 & $\mathrm{LR} / \mathrm{DM}$ & Biomarkers reassessment & 25 & 30 & 0 \\
\hline Zheng $2001[30]$ & 52 & ALM & Biomarkers reassessment & 6 & & \\
\hline Tanner $2001[6]$ & 45 & $\mathrm{LR} / \mathrm{DM}$ & Biomarkers reassessment & & & 0 \\
\hline Simon 2001 [25] & 125 & ALM & Biomarkers reassessment & & & 3 \\
\hline Gancberg 2002 [1] & 100 & $\mathrm{DM}$ & Biomarkers reassessment & & & 6 \\
\hline Vincent-Salomon 2002 [29] & 44 & $\mathrm{DM}$ & Biomarkers reassessment & & & 4 \\
\hline Edgerton 2003 [13] & 113 & $\mathrm{LR} / \mathrm{DM}$ & Biomarkers reassessment & & & 20 \\
\hline Iguchi 2003 [15] & 87 & ALM & Biomarkers reassessment & 24 & & \\
\hline Carlsson 2004 [12] & 47 & ALM & Biomarkers reassessment & & & 0 \\
\hline Regitnig 2004 [21] & 31 & $\mathrm{DM}$ & Biomarkers reassessment & & & 10 \\
\hline Gong 2005 [2] & 60 & $\mathrm{ALM} / \mathrm{LR} / \mathrm{DM}$ & Biomarkers reassessment & & & 3 \\
\hline Zidan 2005 [7] & 58 & LR/DM & Biomarkers reassessment & & & 14 \\
\hline Lower 2005 [20] & 200 & LR/DM & Reports review & 30 & 39 & \\
\hline Tapia 2007 [26] & 105 & $\mathrm{DM}$ & Biomarkers reassessment & & & 3 \\
\hline Guarneri 2008 [3] & 75 & LR/DM & Reports review & 22 & 36 & 16 \\
\hline Gomez-Fernandez 2008 [14] & 278 & $\mathrm{LR} / \mathrm{DM}$ & Biomarkers reassessment & 3 & & \\
\hline Santinelli 2008 [22] & 119 & $\mathrm{ALM} / \mathrm{LR} / \mathrm{DM}$ & Biomarkers reassessment & & & 14 \\
\hline Broom 2009 [11] & 100 & $\mathrm{DM}$ & Reports review & 18 & 37 & 5 \\
\hline Simmons 2009 [5] & 29 & $\mathrm{DM}$ & Biomarkers reassessment & 12 & 28 & 8 \\
\hline Liedtke 2009 [18] & 211 & LR/DM & Reports review & 18 & 40 & 14 \\
\hline Idirisinghe 2010 [4] & 117 & LR/DM & Biomarkers reassessment & 16 & 38 & 5 \\
\hline Sari 2010 [23] & 78 & LR/DM & Biomarkers reassessment & 36 & 54 & 15 \\
\hline Thompson 2010 [27] & 137 & LR/DM & Biomarkers reassessment & 10 & 25 & 3 \\
\hline Amir 2010 [9] & 271 & LR/DM & Biomarkers reassessment & 13 & 34 & 5 \\
\hline Locatelli 2010 [19] & 255 & DM (liver) & Reports review & 14 & 48 & 14 \\
\hline
\end{tabular}

$A L M$ axillary lymph node metastases, $L R$ local recurrences, $D M$ distant metastases, $E R$ estrogen receptor, $P R$ progesterone receptor 
with in situ, multifocal or bilateral breast PT were excluded. In cases with multiple LR or DM, we considered samples obtained from the first (chronologically) detected LR or DM site. For each PT, the following information was obtained from pathology reports: patient age, histological type, tumour size, grading, ER, PR and HER-2 status.

Data regarding adjuvant therapy and follow-up were retrieved from the files of the department of oncology. Tissue samples were fixed in $10 \%$ buffered formalin for 20-24 h before processing and embedding. Hormone receptors status was evaluated by immunohistochemistry (IHC), while HER-2 status by IHC and silver in situ hybridisation (SISH). All samples were reassessed with the same validated staining techniques to reduce interlaboratory variability and reviewed by a single dedicate breast pathologist (G.B.) to decrease inter-observer variability. These results were compared to the original report; this comparison was possible in 280 samples for ER and PR and in 82 samples for HER-2 because, in our institute, it has been evaluated routinely since 2005 .

A high loss rate of PR in LR and DM has been previously reported (Table 1). On this way, we examined whether this finding could have any clinical impact, evaluating metastasis free survival (MFS), defined as elapsed months since LR to first DM, in the subset of patients with ER positive PT and LR, but with different PR status. ER negative tumours were excluded because there were no ER negative/PR positive tumours, and then the choice of therapy was not influenced by PR status. Patients with DM prior or synchronous to LR were excluded, because patient's management was determined by the presence of DM, regardless of LR features.

\section{Immunohistochemistry}

IHC to detect hormone receptors was performed with the CONFIRM $^{\circledR}$ anti-ER clone SP1, rabbit monoclonal primary antibody and CONFIRM ${ }^{\circledR}$ anti-PR clone 1E2 (VMS, Tucson AZ, USA) using an automated BenchMark XT staining system (VMS, Tucson AZ, USA) with a reduced $\mathrm{CC} 1 \mathrm{pH} 8.2$ for $30 \mathrm{~min}$ ) unmasking protocol. Sections were incubated at $37^{\circ} \mathrm{C}$ for $20 \mathrm{~min}$ and then developed with the UltraView Universal Dab Detection Kit. According to the ASCO/CAP guidelines, we defined as positive tumours with $\mathrm{ER} / \mathrm{PR} \geq 1 \%$ [32]; we considered as shifted those cases that changed from $\geq 1 \%$ to $<1 \%$ and vice versa.

HER-2 was performed using the primary antibody PATHWAY ${ }^{\circledR}$ anti-HER2/neu clone 4B5 (VMS, Tucson AZ, USA) in the automated BenchMark XT staining system (VMS, Tucson, AZ, USA) using a reduced $(\mathrm{pH} 8.2$ for $30 \mathrm{~min}$ ) CC1-unmasking protocol. Sections were incubated at $37^{\circ} \mathrm{C}$ for $16 \mathrm{~min}$ and developed with the UltraView Universal Dab Detection Kit.
According to ASCO/CAP guidelines, HER-2 expression was scored as 0 (no staining or weak/moderate, incomplete/ complete staining in $\leq 10 \%$ of cells), $1+$ (weak and incomplete staining in $>10 \%$ of cells), $2+$ (weak/moderate complete staining in $>10 \%$ of cells or strong, complete staining in $\leq 30 \%$ of cells) and $3+$ (strong, complete staining in $>30 \%$ of cells) [33].

In addition, we detected Ki-67 (CONFIRM ${ }^{\circledR}$ anti-Ki-67 clone 30-9, rabbit monoclonal primary antibody) and Ecadherin (clone 36 , mouse monoclonal primary antibody) in all cases using an automated BenchMark XT staining system (VMS, Tucson, AZ, USA) with a reduced CC1 (pH 8.2 for $30 \mathrm{~min}$ ) unmasking protocol. Sections were incubated at $37^{\circ} \mathrm{C}$ for $20 \mathrm{~min}$ and then developed with the UltraView Universal Dab Detection Kit.

\section{Silver in situ hybridisation}

SISH was performed in BenchMarK XT staining system (VMS, Tucson AZ, USA) according to the manufacturer's instructions. Testing for the HER-2 gene and chromosome 17 was performed on sequential sections. Briefly, formalinfixed, paraffin-embedded tissues were cut in $4.5 \mu \mathrm{m}$ thick sections, put on polarized slides, dried overnight at $40^{\circ} \mathrm{C}$ and placed in the automated staining system (one slide for each probe). The principal steps were heat pre-treatment with citrate buffer $\mathrm{pH} 6$ at $90^{\circ} \mathrm{C}$, enzymatic digestion with protease at $37^{\circ} \mathrm{C}$ for $8 \mathrm{~min}$, probe dispensation, denaturation at $95^{\circ} \mathrm{C}$ for $8 \mathrm{~min}$, hybridisation at $52 / 54^{\circ} \mathrm{C}$ for $3 \mathrm{~h}$, stringent washes, indirect detection and counterstaining with haematoxylin. Slides were progressively dehydrated with increasing alcohol concentrations, cleared in xylene and mounted. HER-2 3-in-1 xenograft control slides were used as reaction and quality controls. The number of signal deposits was counted in 20 tumour nuclei in two distinct areas, in the slide reactive for HER-2 and in the same areas in the slide reactive for chromosome 17. The HER-2/ chromosome 17 ratio was calculated and scored according to ASCO/CAP guidelines: ratio $<1.8$, HER-2 gene not amplified; ratio $>2.2$, HER-2 gene amplified; ratio between 1.8 and 2.2, uncertain [33].

Discordant HER-2 status was considered when there was a shift from $0,1+, 2+$ (SISH non-amplified) IHC to $2+$ (SISH amplified) or $3+$ IHC and vice versa. In case of discordance between IHC and SISH, the HER-2 was defined according to the SISH status. In our routine work up for breast cancer, the discordance rate between IHC and SISH to HER-2 determination is $2.8 \%$.

Statistical analysis

Agreement for ER, PR and HER-2 between PT and corresponding relapses was expressed by discordance 
percentage. Significant changes in one direction (positive or negative) of ER, PR and HER-2 between PT and corresponding metastases were calculated using the McNemar's test. Comparisons of percentages between groups were performed using the chi-square or Fisher's exact test. The MFS in the group of patients considered was described by the Kaplan-Meier method and compared with the use of the log-rank test. A two-sided $P$ value of 0.05 was considered a statistically significant difference.

A multivariable Cox proportional hazard regression model was used to evaluate the independent prognostic relevance of the following factors for MFS: PT pathological size (T1 vs T2-T4); pathological node status (negative vs positive $\leq 3$ vs positive $>3$ ); PT histological grade (grade 1-2 vs grade 3), PT Ki-i67 level (examined as continuous variable); PT/LR HER-2 status (negative vs positive); PT/LR ER positive proportion (examined as continuous variable); LR free survival ( $\leq 1$ year vs $1-$ 5 years vs $>5$ years); PR status (PR positive in PT and LR vs $\mathrm{PR}$ positive $\mathrm{PT}$ and negative LR vs $\mathrm{PR}$ negative in PT and LR). Stata/IC for Windows version 11.1 was used for all analyses.

\section{Results}

Pathological results

We analysed 140 PT and their corresponding relapses (90 LR and $50 \mathrm{DM}$ ). Clinical and pathological features of the PT are shown in Table 2. The mean interval of LR was 55 months (range, 5-232 months); sites of LR were: breast (21), chest wall (44), axilla (23) and homolateral clavicular nodes (two). All samples of LR were surgical specimens. Forty-six DM were metachronous and four synchronous. The mean interval of metachronous DM was 73.6 months (range, 6-216 months). The sites of metachronous DM were: liver (five), lung (nine), pleura (two), bone (ten), skin (three), ovary (three), peritoneum (one), stomach (five), duodenum (three), thyroid (one), cervix (one) and node (three). The sites of synchronous DM were: colon (one), bone (one), node (one) and brain (one). Twenty-seven samples of DM were surgical samples, whereas 23 were bioptic specimens.

The results regarding ER, PR and HER-2 status in PT and corresponding metastatic sites are shown in Table 3. ER and PR status was available for all 140 paired samples, whereas HER-2 status for 136 paired samples, since four cases were not evaluable due to unreliable tissue processing. In these cases, the chromosome 17 marker could not be identified by SISH analysis. We found ten cases with significant changes between the original report and the
Table 2 Clinical and pathologic features of 140 primary breast tumours

\begin{tabular}{|c|c|}
\hline & Primary tumours \\
\hline \multicolumn{2}{|l|}{ Age (years) } \\
\hline Mean & 61.7 \\
\hline Range & $34-93$ \\
\hline \multicolumn{2}{|l|}{ Size $(\mathrm{cm})$} \\
\hline Mean & 2.6 \\
\hline Range & $0.5-9.5$ \\
\hline \multicolumn{2}{|l|}{ Histologic type } \\
\hline Ductal & 101 \\
\hline Lobular & 32 \\
\hline Others & 7 \\
\hline \multicolumn{2}{|l|}{ Grading } \\
\hline G1 & 24 \\
\hline $\mathrm{G} 2$ & 63 \\
\hline G3 & 53 \\
\hline \multicolumn{2}{|l|}{ ER status } \\
\hline Positive & 111 \\
\hline Negative & 29 \\
\hline \multicolumn{2}{|l|}{ PR status } \\
\hline Positive & 91 \\
\hline Negative & 49 \\
\hline \multicolumn{2}{|l|}{ HER-2 status } \\
\hline Positive & 18 \\
\hline Negative & 118 \\
\hline Non-informative & 4 \\
\hline \multicolumn{2}{|l|}{ Therapy } \\
\hline None & 43 \\
\hline $\mathrm{CT}$ & 25 \\
\hline HT & 24 \\
\hline $\mathrm{CT}$ and $\mathrm{HT}$ & 36 \\
\hline Not available & 12 \\
\hline
\end{tabular}

$E R$ estrogen receptor, $P R$ progesterone receptor, $C T$ chemotherapy, $H T$ hormone therapy

reassessed IHC staining. In five cases, there was a different ER value, while in the remaining cases differences in PR were seen, all in the PT.

A discrepancy in ER was present in nine $(6.4 \%)$ of paired samples, eight (7.2\%) lost and one (3.4\%) gained ER $(P=0.04)$. In four (three loss and one gain) of these nine paired samples, there was a similar discrepancy in PR, while in the other five cases with ER loss, PR was negative in both PT and relapse.

A change in PR status was present in $30(21.4 \%)$ of paired samples; 25 (27.5\%) lost and five (10.2\%) gained PR $(P=0.0003)$. The change rate between PR and ER was statistically significant $(P=0.0004)$.

Comparison between LR and DM showed a difference not statistically significant with regards to the rate of 
Table 3 Change of ER, PR and HER-2 in different metastatic sites

\begin{tabular}{|c|c|c|c|c|c|c|c|c|c|}
\hline & \multicolumn{3}{|l|}{ ER } & \multicolumn{3}{|l|}{ PR } & \multicolumn{3}{|l|}{ HER-2 } \\
\hline & Change & Pos-neg & Neg-pos & Change & Pos-neg & Neg-pos & Change & Pos-neg & Neg-pos \\
\hline LR & $5 / 90(5.5 \%)$ & $5 / 70(7.1 \%)$ & $0 / 20$ & $14 / 90(15.5 \%)$ & $11 / 58(18.9 \%)$ & $3 / 32(9.3 \%)$ & $1 / 88(1.1 \%)$ & $0 / 11$ & $1 / 77(1.3 \%)$ \\
\hline $\mathrm{DM}$ & $4 / 50(8 \%)$ & $3 / 41(7.3 \%)$ & $1 / 9(11.1 \%)$ & $16 / 50(32 \%)$ & $14 / 33(42.4 \%)$ & 2/17 (11.8\%) & $0 / 48$ & $0 / 7$ & $0 / 41$ \\
\hline Total & $9 / 140(6.4 \%)$ & $8 / 111(7.2 \%)$ & $1 / 29(3.4 \%)$ & $30 / 140(21.4 \%)$ & $25 / 91(27.5 \%)$ & $5 / 49(10.2 \%)$ & $1 / 136(0.7 \%)$ & $0 / 18$ & $1 / 118(0.8 \%)$ \\
\hline
\end{tabular}

$L R$ local recurrences, $D M$ distant metastases, $E R$ estrogen receptor, $P R$ progesterone receptor

change in ER $(P=0.72)$, while it showed a trend towards a statistical significance for change in PR, more frequent in $\mathrm{DM}$ than in $\operatorname{LR}(P=0.03)$. This trend was maintained even in the group of untreated patients $(P=0.02)$.

HER-2 change was present in 5 of 136 paired samples (3.7\%) using IHC and in only one paired samples after SISH $(0.7 \%)$. In four of these IHC-HER-2-shifted paired samples, there was discordance between IHC and SISH; one sample was IHC positive and SISH negative, whereas three were IHC negative and SISH positive. Analysis of the our case with HER-2 shift showed a PT negative to IHC and not amplified to SISH, while the axillary recurrence, developed 96 months after mastectomy and axillary lymph node dissection, showed IHC positivity and SISH amplification. The comparison of the two tumours demonstrated a shift from primary ductal type carcinoma (E-cadherin positivity) to lobular type carcinoma (E-cadherin negativity) (Fig. 1). In no other case, there was a change in histologic type and E-cadherin expression between PT and corresponding relapse.

The relationship between hormone receptor status and therapy is shown in Table 4. Thirty-six patients were treated with chemotherapy associated with hormone therapy, 25 were treated with chemotherapy only and 24 were treated with hormone therapy only. Forty-three patients received no adjuvant therapy. In this latter group, we included the four patients with synchronous DM, considering that hormone receptor status could not be affected by therapy. Only five patients were treated with trastuzumab (two with LR and three with DM). There was no clinical information in 12 patients. There were not statistically significant differences in ER change among the four groups of patients, whereas there was a statistically significant PR loss in patients treated with chemotherapy and hormone therapy $(P=0.0005)$. There were no significant associations between histological type (ductal vs lobular), grading (G1-G2 vs G3), Ki-67(low < median value, $14 \%$ vs high $\geq$ median value, 14 ) and hormone receptors shift (data not shown).

\section{Clinical results}

The analysis of MFS in the subset of patients with ER positive PT and LR, but with different PR status was possible in 56 patients: 20 patients with ER negative PT, five patients with ER negative LR and nine patients with DM prior or synchronous to LR were excluded. Out of 56 patients evaluated, there was only one patient with PR negative PT and positive LR. This single patient was excluded from analysis. Therefore, we overall analysed MFS in 55 patients.

Kaplan-Meier MFS curves (Fig. 2) showed a significant difference in MFS among groups of patients with ER positive local recurrence but different PR status: primary tumour and local recurrence both PR positive (group A, 40 patients); primary tumour and local recurrence both $\mathrm{PR}$ negative (group B, seven patients) and primary tumour PR positive and local recurrence PR negative (group $C$, eight patients). Group $\mathrm{C}$ patients had significantly worse MFS (median 24.1 months) compared with group A patients (median 111.8 months) $(\log -\mathrm{rank}=0.005)$. Multivariate analysis showed that PR status in LR was independently associated with MFS and that PR loss in LR (group C) was also strongly associated with poor outcome: hazard ratio, 8.9 (95\% CI, 2.3-34.5) $(P=0.002)$.

\section{Discussion}

The development of target therapy has changed the prognosis of patients both in adjuvant and metastatic setting [34-38]. Although therapy targets metastases, the hormone receptors and HER-2 status are almost always evaluated on PT [1-3, 5-7]. Thus, it is crucial to determine whether there is concordant biomarkers expression between PT and corresponding metastasis, since the data available from literature show very discordant results about this issue (Table 1) [1-30]. In almost all previous reports, the adopted threshold of positivity for hormone receptors is $\geq 10 \%$ of neoplastic cells $[3-5,10,14-16,18,28,30]$, while for HER-2 is $>10 \%$ of neoplastic cells with intense continuous membrane staining for IHC $[1,3,7,13,22,25]$ or ratio $>2$ for in situ hybridisation $[1-3,13,21,26]$. The recent ASCO/CAP guidelines considered receptor positive for a tumour with a minimum of $1 \%$ of positive tumour cells [32] and HER-2 positive for a tumour with an intense 
Fig. 1 Different morphology (H\&E) between ductal like primary tumour (a) and lobular like local recurrence (b). Immunohistochemistry showed different staining for E-cadherin and HER-2 between the primary tumour (c, e) and the recurrence $(\mathbf{d}, \mathbf{f})$
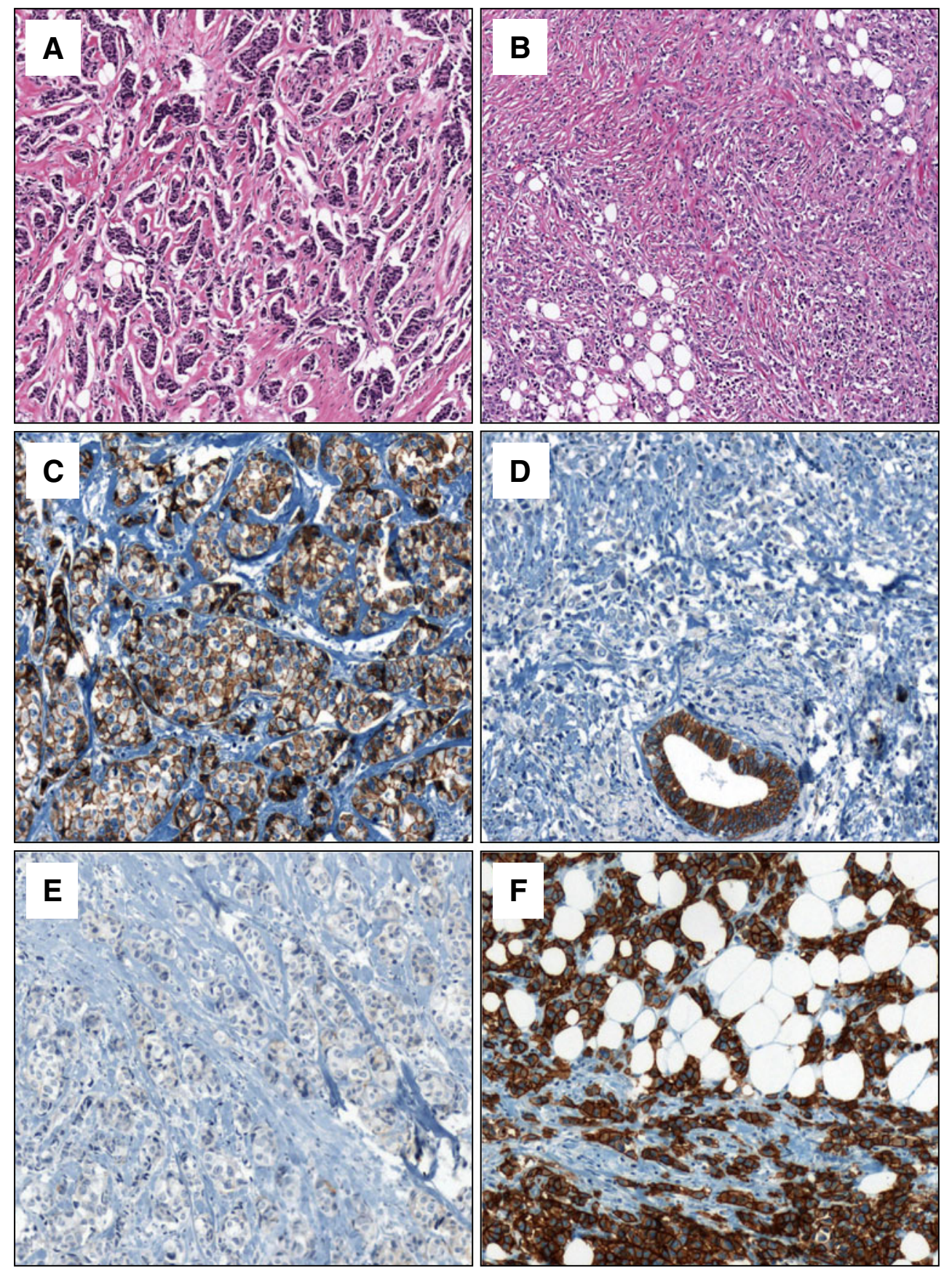

Table 4 Correlation between changes in ER, PR and therapy

\begin{tabular}{|c|c|c|c|c|c|c|}
\hline & \multicolumn{3}{|l|}{ ER } & \multicolumn{3}{|l|}{ PR } \\
\hline & Change & Pos-neg & Neg-pos & Change & Pos-neg & Neg-pos \\
\hline $\mathrm{CT}$ & $0 / 25$ & $0 / 10$ & $0 / 15$ & $2 / 25(8 \%)$ & $0 / 8$ & $2 / 17(11.7 \%)$ \\
\hline HT & $1 / 24(4.1 \%)$ & $1 / 24(4.1 \%)$ & $0 / 0$ & $6 / 24(25 \%)$ & $4 / 18(22.2 \%)$ & $2 / 6(33 \%)$ \\
\hline $\mathrm{CT}$ and $\mathrm{HT}$ & $2 / 36(5.5 \%)$ & $2 / 34(5.9 \%)$ & $0 / 2$ & $12 / 36(33.3 \%)$ & $12 / 29(41.4 \%)$ & $0 / 7$ \\
\hline None & $6 / 43(13.9 \%)$ & $5 / 31(16.1 \%)$ & $1 / 12(8.3 \%)$ & $6 / 43(13.9 \%)$ & $5 / 26(19.2 \%)$ & $1 / 17(5.9 \%)$ \\
\hline
\end{tabular}

$E R$ estrogen receptor, $P R$ progesterone receptor, $C T$ chemotherapy, $H T$ hormone therapy 
Fig. 2 Kaplan-Meier estimate of metastasis free survival according to $\mathrm{PT} / \mathrm{LR}$ receptor status. Groups $(A, B, \mathrm{C})$ are defined in Clinical results

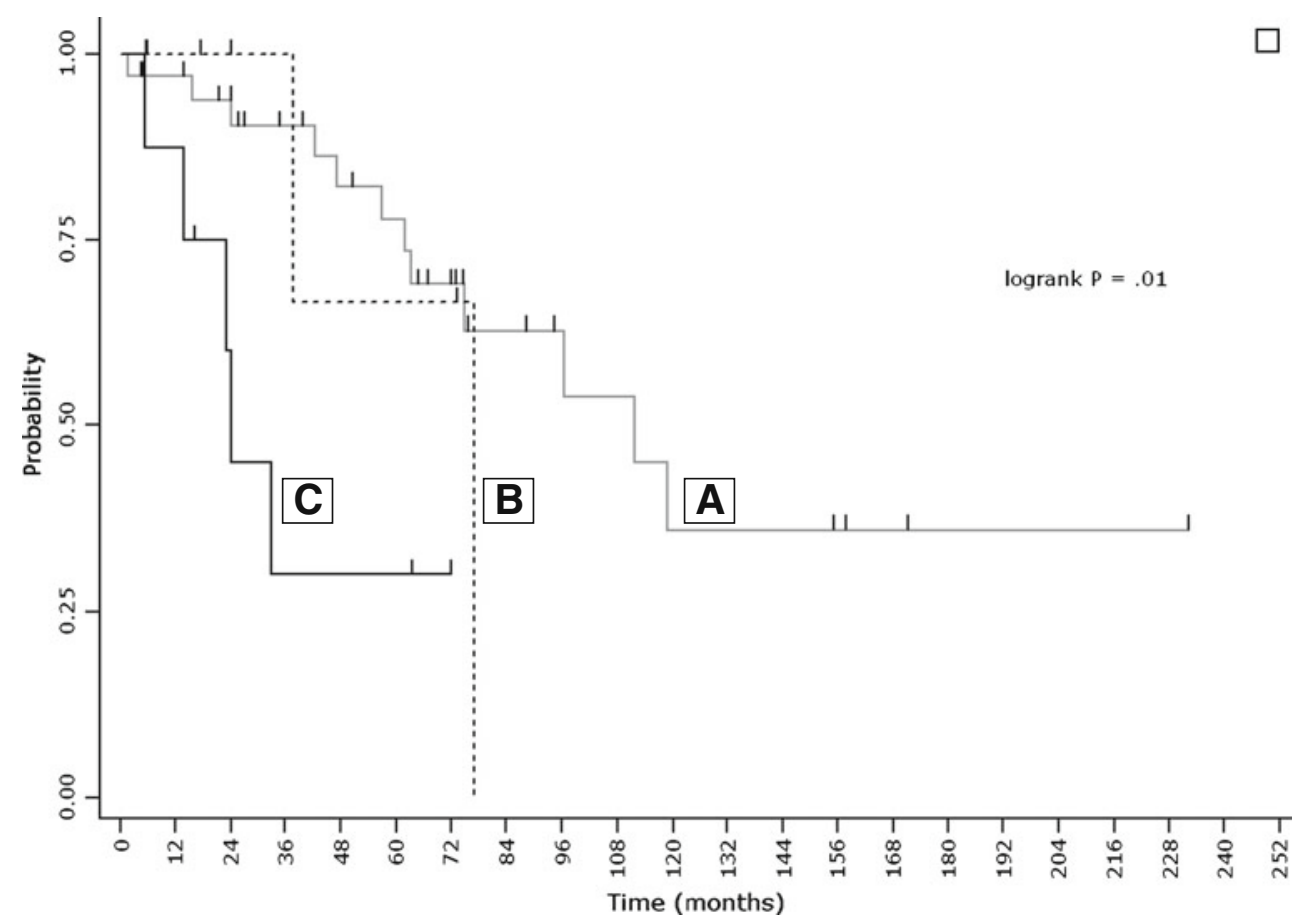

continuous staining in $>30 \%$ of neoplastic cells in IHC and/ or a ratio $>2.2$ in situ hybridisation [33]. In this work, we have adopted the positivity threshold proposed by the ASCO/CAP guidelines. We reassessed ER, PR and HER-2 status in PT and corresponding metastasis in 140 paired samples including $90 \mathrm{LR}$ and $50 \mathrm{DM}$.

We found a significant change for hormone receptors between the original report and the reassessed IHC staining in $3.6 \%$ of samples, all in the PT. In these tumour samples, the original report was done before 2000. Amir et al. reported a change in $5.8 \%, 11.5 \%$ and $8.7 \%$ after reassessment for ER, PR and HER-2, respectively [9]. This discrepancy might be due to differences in analytic factors such as use of manual or automated methods, tests reagents and type of antigen retrieval.

The rate of change in ER staining was $6.1 \%$. Overall, there was a trend towards a statistical significance for ER loss $(P=0.04)$. ER change was not affected by therapy. In agreement with Shimizu et al. [24], in the majority of our cases with ER change, there was a corresponding change in PR status. This is likely due to fact that PR is regulated by ER [39].

A change in PR status was seen in $21.4 \%$ of cases, significantly more frequently than ER change $(P<0.0001)$. These data are in agreement with the majority of previous publications [4, 8, 9, 11, 17-20, 23, 24, 27]. Overall, a PR positive PT with a negative relapse was the most frequent event $(P=0.0003)$.

Overall, we had six cases in which the PT was negative for hormone receptors (one ER and five PR), but the corresponding relapse was positive. This event has been reported by other authors $[4,9,11,15,17,19,20,23,27]$. False negative assessment in PT cannot be excluded; however, our cases showed hormone receptors positive control in normal breast tissue associated with the PT, ruling out the possibility that technical factors, including poor fixation, influenced the different receptors status. While the loss of hormone receptors, during metastasis process, might be related with clonal selection or tumour dedifferentiation, these mechanisms could not explain hormone receptors gain. Molecular analyses showed the presence of different clones of cells having different genetic profile in the same tumour; metastasis might be established by one of these clones. The parallel progression model posits parallel, independent evolution of metastasis arising from early disseminated tumour cells clone rather than a linear progression of primary tumour to metastasis [40].

HER-2 change was present in $3.7 \%$ of paired samples using IHC and in only $0.7 \%$ after SISH analysis. In four of these five IHC-HER-2-shifted paired samples, there was discordance between IHC and SISH. In discordant cases, the reassessment of HER-2 status on PT and relapse with both techniques is warranted. The analysis of the case with HER-2 shift showed an HER-2 negative PT to IHC and SISH and a HER-2 positive axillary recurrence to IHC and SISH. The comparison of the two tumours demonstrated a shift from primary ductal type carcinoma (E-cadherin positivity) to lobular type carcinoma (E-cadherin negativity) (Fig. 2). Although Wu et al. reported a similar case of E-cadherin positive primary ductal carcinoma with corresponding multiple metastases characterized by lobular morphology and E-cadherin loss 
expression [41], a second tumour arising from residual mammary parenchyma rather than a real recurrence can be supposed. Indeed, there are no reliable morphologic or clinical criteria to distinguish LR from secondary tumour. Clinically, controlateral cancer is generally considered to represent independent tumour, in ipsilateral disease, tumour having a longer mean time to recurrence or occurring in different quadrant from the initial tumour is also regarded as new primary tumour. Finally, concerning pathological features, the presence of in situ carcinoma, different histological type or better differentiation of second tumour may help in identifying independent tumours [42]. Research using genomic analyses may replace these criteria [43].

Changes in PR status were more frequent in DM than LR $(P=0.003)$ and this trend was maintained in patients not undergoing any therapy $(P=0.002)$. Most of previous papers, investigating the difference in hormone receptor status between DM and LR, have shown a similar rate of discordance between DM and LR [17, 20, 23, 27], while Idirisinghe et al. demonstrated a higher rate of discordance for both ER and PR in DM [4]. A higher rate of HER-2 shift in DM in comparison to LR has been reported by several authors $[2,4,21,22,26]$. Since LR was made up exclusively of surgical specimens and nearly half of DM of bioptic specimens, one possible reason for this difference might be related to the size of the samples analysed. The discordance rate of hormone receptors and HER-2 between core biopsy and corresponding surgical specimen in breast cancer varies from $1 \%$ [44] to $18.7 \%$ [45] for hormone receptors and from $1.2 \%$ [46] to $13.5 \%$ [44] for HER-2. However, in our cases of DM, there was no statistically significant difference in ER and PR change between bioptic $(n=23)$ and surgical $(n=27)$ specimens $(P=0.61$ and $P=0.55$, respectively). Thus, it is likely that the greater degree of biomarkers change in DM compared with either LR likely reflects the complex biologic process to establish growth in a new site. The basic steps of metastasis include the progression of the PT towards dispersion of cancer cells through the blood vessels. Circulating cancer cells could infiltrate distant organs and, in the new microenvironment, might proceed towards overt metastasis [47].

Regarding therapeutic implications, since there were no ER negative/PR positive tumour samples, there was a theoretical change in clinical management in $7.3 \%$ of patients corresponding to nine cases with ER change and to case with HER-2 change. Amir et al. [9], Locatelli et al. [19] and Thompson et al. [27] reported a therapeutic change of management in $15.1 \%, 12.1 \%$ and $17.5 \%$, respectively. Simmons et al. [5] demonstrated a significant change in patient management in 6 of 29 cases $(20 \%)$. However, in that prospective study, the diagnosis of suspicious "metastatic" biopsy was a benign lesion in three cases and lymphoma in one case. Consequently, in only 2 of 25 cases $(8 \%)$ was there a change in management due to a genuine change in biomarker status.

Concerning the relation between hormone receptor change and therapy, we showed that ER change was not affected by therapy $(P=0.7)$, whereas a significant change was observed only for PR loss in patients who underwent chemotherapy and hormone therapy $(P<0.0005)$. Li et al. demonstrated a lack of influence of hormone therapy and chemotherapy on ER and PR status [17], while Idirisinghe et al. showed a correlation between ER and PR loss and hormone therapy [4]. Sequential breast cancer biopsies have shown that ER levels are reduced slightly with intervening endocrine therapy, while PR levels decrease more dramatically with up to half of tumours completely losing PR expression when resistance develops [48].

Few studies have shown a shorter survival among women with ER negative metastatic and locally recurrent tumours, regardless of the primary tumour ER status [4, 20], while whether and how the loss of PR affects the clinical course of ER positive/PR negative metastatic tumours remains to be clarified [48]. The study of Brankovic-Magic et al., based on reports review of 23 breast cancer and corresponding metastases, suggests that PR loss in metastasis may be an important marker in predicting response failure to endocrine therapy in metastatic disease [49].

In our study, the analysis of patients with ER positive PT and LR showed that the MFS was significantly worse in patients with a PR positive PT and negative LR than in those with both PR positive PT and LR $(\log$-rank $=0.01)$ (Fig. 2). Noteworthy, all the eight patients with ER positive PT and LR who lost PR in LR had received therapy after LR diagnosis: six had hormone therapy, one had chemotherapy and one hormone therapy associated to chemotherapy. The very short median MFS time (24 months) observed in this group of patients seems to indicate that hormone therapy, received by seven out of eight PR-shifted patients, may be not enough to treat this disease. A more aggressive approach by combining extensive local therapy with chemotherapy and hormone therapy is probably required. Nevertheless, our data clearly indicate that PRshifted patients have a poor prognosis and should be accurately followed-up after their LR.

In summary, in the present study, a change between PT and corresponding metastasis was frequent for PR and less frequent for ER, whereas it was very rare for HER-2. In cases with HER-2 shift, reassessment of HER-2 status on PT and corresponding relapse with both techniques (IHC and in situ hybridisation) is warranted. Changes in biomarkers may occur sporadically, preferably in DM compared to LR, although the loss of PR appears to be affected by chemotherapy associated to hormone therapy. In 
patients with ER positive PT and LR, PR loss in LR correlates with a more aggressive behaviour of the tumour.

Acknowledgements The authors thank Patrick Moore for the English revision of the manuscript.

Conflicts of interest The authors declare that they have no conflicts of interest.

Open Access This article is distributed under the terms of the Creative Commons Attribution Noncommercial License which permits any noncommercial use, distribution, and reproduction in any medium, provided the original author(s) and source are credited.

\section{References}

1. Gancberg D, Di Leo A, Cardoso F, Rouas G, Pedrocchi M, Paesmans M, Verhest A, Bernard-Marty C, Piccart MJ, Larsimont D (2002) Comparison of HER-2 status between primary breast cancer and corresponding distant metastatic sites. Ann Oncol 13 (7):1036-1043

2. Gong Y, Booser DJ, Sneige N (2005) Comparison of HER-2 status determined by fluorescence in situ hybridization in primary and metastatic breast carcinoma. Cancer 103(9):1763-1769

3. Guarneri V, Giovannelli S, Ficarra G, Bettelli S, Maiorana A, Piacentini F, Barbieri E, Dieci MV, D’Amico R, Jovic G, Conte $P$ (2008) Comparison of HER-2 and hormone receptor expression in primary breast cancers and asynchronous paired metastases: impact on patient management. Oncologist 13 (8):838-844

4. Idirisinghe PK, Thike AA, Cheok PY, Tse GM, Lui PC, FookChong S, Wong NS, Tan PH (2010) Hormone receptor and cERBB2 status in distant metastatic and locally recurrent breast cancer. Pathologic correlations and clinical significance. Am J Clin Pathol 133(3):416-429

5. Simmons C, Miller N, Geddie W, Gianfelice D, Oldfield M, Dranitsaris G, Clemons MJ (2009) Does confirmatory tumor biopsy alter the management of breast cancer patients with distant metastases? Ann Oncol 20(9):1499-1504

6. Tanner M, Jarvinen P, Isola J (2001) Amplification of HER-2/neu and topoisomerase IIalpha in primary and metastatic breast cancer. Cancer Res 61(14):5345-5348

7. Zidan J, Dashkovsky I, Stayerman C, Basher W, Cozacov C, Hadary A (2005) Comparison of HER-2 overexpression in primary breast cancer and metastatic sites and its effect on biological targeting therapy of metastatic disease. Br J Cancer 93(5):552-556

8. Johnston SR, Saccani-Jotti G, Smith IE, Salter J, Newby J, Coppen M, Ebbs SR, Dowsett M (1995) Changes in estrogen receptor, progesterone receptor, and pS2 expression in tamoxifenresistant human breast cancer. Cancer Res 55(15):3331-3338

9. Amir R, Clemons M, Freedman OC, Miller N, Coleman RE, Purdie C, Jordan L, Quinlan P, Thompson AM (2010) Tissue confirmation of disease recurrence in patients with breast cancer: pooled analysis of two large prospective studies. J Clin Oncol $28: 15 \mathrm{~s}$

10. Andersen J, Poulsen HS (1988) Relationship between estrogen receptor status in the primary tumor and its regional and distant metastases. An immunohistochemical study in human breast cancer. Acta Oncol 27(6A):761-765

11. Broom RJ, Tang PA, Simmons C, Bordeleau L, Mulligan AM, O’Malley FP, Miller N, Andrulis IL, Brenner DM, Clemons
MJ (2009) Changes in estrogen receptor, progesterone receptor and Her-2/neu status with time: discordance rates between primary and metastatic breast cancer. Anticancer Res 29 (5):1557-1562

12. Carlsson J, Nordgren H, Sjostrom J, Wester K, Villman K, Bengtsson NO, Ostenstad B, Lundqvist H, Blomqvist C (2004) HER2 expression in breast cancer primary tumours and corresponding metastases. Original data and literature review. $\mathrm{Br}$ J Cancer 90(12):2344-2348

13. Edgerton SM, Moore D 2nd, Merkel D, Thor AD (2003) erbB-2 (HER-2) and breast cancer progression. Appl Immunohistochem Mol Morphol 11(3):214-221

14. Gomez-Fernandez C, Daneshbod Y, Nassiri M, Milikowski C, Alvarez C, Nadji M (2008) Immunohistochemically determined estrogen receptor phenotype remains stable in recurrent and metastatic breast cancer. Am J Clin Pathol 130(6):879-882

15. Iguchi C, Nio Y, Itakura M (2003) Heterogeneic expression of estrogen receptor between the primary tumor and the corresponding involved lymph nodes in patients with nodepositive breast cancer and its implications in patient outcome. $\mathrm{J}$ Surg Oncol 83(2):85-93

16. Kuukasjarvi T, Kononen J, Helin H, Holli K, Isola J (1996) Loss of estrogen receptor in recurrent breast cancer is associated with poor response to endocrine therapy. J Clin Oncol 14(9):25842589

17. Li BD, Byskosh A, Molteni A, Duda RB (1994) Estrogen and progesterone receptor concordance between primary and recurrent breast cancer. J Surg Oncol 57(2):71-77

18. Liedtke C, Broglio K, Moulder S, Hsu L, Kau SW, Symmans WF, Albarracin C, Meric-Bernstam F, Woodward W, Theriault RL, Kiesel L, Hortobagyi GN, Pusztai L, Gonzalez-Angulo AM (2009) Prognostic impact of discordance between triple-receptor measurements in primary and recurrent breast cancer. Ann Oncol 20(12):1953-1958

19. Locatelli MA, Curigliano G, Fumagalli L, Bagnardi V, Aurilio G, Della Vigna P, Monfardini L, Giudici S, Viale G, Goldhirsch A (2010) Should liver metastases of breast cancer be biopsied to improve treatment choice? J Clin Oncol 28:18s

20. Lower EE, Glass EL, Bradley DA, Blau R, Heffelfinger S (2005) Impact of metastatic estrogen receptor and progesterone receptor status on survival. Breast Cancer Res Treat 90(1):65-70

21. Regitnig P, Schippinger W, Lindbauer M, Samonigg H, Lax SF (2004) Change of HER-2/neu status in a subset of distant metastases from breast carcinomas. J Pathol 203(4):918-926

22. Santinelli A, Pisa E, Stramazzotti D, Fabris G (2008) HER-2 status discrepancy between primary breast cancer and metastatic sites. Impact on target therapy. Int J Cancer 122(5):999-1004

23. Sari E, Guler G, Hayran M, Gullu I, Altundag K, Ozisik Y (2010) Comparative study of the immunohistochemical detection of hormone receptor status and HER-2 expression in primary and paired recurrent/metastatic lesions of patients with breast cancer. Med Oncol 28(1):57-63

24. Shimizu C, Fukutomi T, Tsuda H, Akashi-Tanaka S, Watanabe T, Nanasawa T, Sugihara K (2000) c-erbB-2 protein overexpression and $\mathrm{p} 53$ immunoreaction in primary and recurrent breast cancer tissues. J Surg Oncol 73(1):17-20

25. Simon R, Nocito A, Hubscher T, Bucher C, Torhorst J, Schraml P, Bubendorf L, Mihatsch MM, Moch H, Wilber K, Schotzau A, Kononen J, Sauter G (2001) Patterns of her-2/neu amplification and overexpression in primary and metastatic breast cancer. J Natl Cancer Inst 93(15):1141-1146

26. Tapia C, Savic S, Wagner U, Schonegg R, Novotny H, Grilli B, Herzog M, Barascud AD, Zlobec I, Cathomas G, Terracciano L, Feichter G, Bubendorf L (2007) HER2 gene status in primary breast cancers and matched distant metastases. Breast Cancer Res 9(3):R31 
27. Thompson AM, Jordan LB, Quinlan P, Anderson E, Skene A, Dewar JA, Purdie CA (2010) Prospective comparison of switches in biomarker status between primary and recurrent breast cancer: the Breast Recurrence in Tissues Study (BRITS). Breast Cancer Res 12(6):R92

28. van Agthoven T, Timmermans M, Dorssers LC, Henzen-Logmans SC (1995) Expression of estrogen, progesterone and epidermal growth factor receptors in primary and metastatic breast cancer. Int J Cancer 63(6):790-793

29. Vincent-Salomon A, Jouve M, Genin P, Freneaux P, Sigal-Zafrani B, Caly M, Beuzeboc P, Pouillart P, Sastre-Garau X (2002) HER2 status in patients with breast carcinoma is not modified selectively by preoperative chemotherapy and is stable during the metastatic process. Cancer 94(8):2169-2173

30. Zheng WQ, Lu J, Zheng JM, Hu FX, Ni CR (2001) Variation of ER status between primary and metastatic breast cancer and relationship to p53 expression*. Steroids 66(12):905-910

31. Carney WP, Leitzel K, Ali S, Neumann R, Lipton A (2007) HER2/neu diagnostics in breast cancer. Breast Cancer Res 9(3):207

32. Hammond ME, Hayes DF, Dowsett M, Allred DC, Hagerty KL, Badve S, Fitzgibbons PL, Francis G, Goldstein NS, Hayes M, Hicks DG, Lester S, Love R, Mangu PB, McShane L, Miller K, Osborne CK, Paik S, Perlmutter J, Rhodes A, Sasano H, Schwartz JN, Sweep FC, Taube S, Torlakovic EE, Valenstein P, Viale G, Visscher D, Wheeler T, Williams RB, Wittliff JL, Wolff AC (2010) American Society of Clinical Oncology/College Of American Pathologists guideline recommendations for immunohistochemical testing of estrogen and progesterone receptors in breast cancer. J Clin Oncol 28(16):2784-2795

33. Wolff AC, Hammond ME, Schwartz JN, Hagerty KL, Allred DC, Cote RJ, Dowsett M, Fitzgibbons PL, Hanna WM, Langer A, McShane LM, Paik S, Pegram MD, Perez EA, Press MF, Rhodes A, Sturgeon C, Taube SE, Tubbs R, Vance GH, van de Vijver M, Wheeler TM, Hayes DF (2007) American Society of Clinical Oncology/College of American Pathologists guideline recommendations for human epidermal growth factor receptor 2 testing in breast cancer. J Clin Oncol 25(1):118-145

34. Arpino G, Weiss H, Lee AV, Schiff R, De Placido S, Osborne CK, Elledge RM (2005) Estrogen receptor-positive, progesterone receptor-negative breast cancer: association with growth factor receptor expression and tamoxifen resistance. J Natl Cancer Inst 97(17):1254-1261

35. Piccart-Gebhart MJ, Procter M, Leyland-Jones B, Goldhirsch A, Untch M, Smith I, Gianni L, Baselga J, Bell R, Jackisch C, Cameron D, Dowsett M, Barrios CH, Steger G, Huang CS, Andersson M, Inbar M, Lichinitser M, Lang I, Nitz U, Iwata H, Thomssen C, Lohrisch C, Suter TM, Ruschoff J, Suto T, Greatorex V, Ward C, Straehle C, McFadden E, Dolci MS, Gelber RD (2005) Trastuzumab after adjuvant chemotherapy in HER2positive breast cancer. N Engl J Med 353(16):1659-1672

36. Pritchard KI, Shepherd LE, O'Malley FP, Andrulis IL, Tu D, Bramwell VH, Levine MN (2006) HER2 and responsiveness of breast cancer to adjuvant chemotherapy. N Engl J Med 354 (20):2103-2111

37. Romond EH, Perez EA, Bryant J, Suman VJ, Geyer CE Jr, Davidson NE, Tan-Chiu E, Martino S, Paik S, Kaufman PA,
Swain SM, Pisansky TM, Fehrenbacher L, Kutteh LA, Vogel VG, Visscher DW, Yothers G, Jenkins RB, Brown AM, Dakhil SR, Mamounas EP, Lingle WL, Klein PM, Ingle JN, Wolmark N (2005) Trastuzumab plus adjuvant chemotherapy for operable HER2-positive breast cancer. N Engl J Med 353 (16):1673-1684

38. Slamon DJ, Leyland-Jones B, Shak S, Fuchs H, Paton V, Bajamonde A, Fleming T, Eiermann W, Wolter J, Pegram M, Baselga J, Norton L (2001) Use of chemotherapy plus a monoclonal antibody against HER2 for metastatic breast cancer that overexpresses HER2. N Engl J Med 344(11):783-792

39. Kim HJ, Cui X, Hilsenbeck SG, Lee AV (2006) Progesterone receptor loss correlates with human epidermal growth factor receptor 2 overexpression in estrogen receptor-positive breast cancer. Clin Cancer Res 12(3 Pt 2):1013s-1018s

40. Arslan C, Sari E, Aksoy S, Altundag K (2011) Variation in hormone receptor and HER-2 status between primary and metastatic breast cancer: review of the literature. Expert Opin Ther Targets 15(1):21-30

41. Wu JM, Fackler MJ, Halushka MK, Molavi DW, Taylor ME, Teo WW, Griffin C, Fetting J, Davidson NE, De Marzo AM, Hicks JL, Chitale D, Ladanyi M, Sukumar S, Argani P (2008) Heterogeneity of breast cancer metastases: comparison of therapeutic target expression and promoter methylation between primary tumors and their multifocal metastases. Clin Cancer Res 14(7):1938-1946

42. Schlechter BL, Yang Q, Larson PS, Golubeva A, Blanchard RA, de las Morenas A, Rosenberg CL (2004) Quantitative DNA fingerprinting may distinguish new primary breast cancer from disease recurrence. J Clin Oncol 22(10):1830-1838

43. Brown M, Bauer K, Pare M (2010) Tumor marker phenotype concordance in second primary breast cancer, California, 19992004. Breast Cancer Res Treat 120(1):217-227

44. Park SY, Kim KS, Lee TG, Park SS, Kim SM, Han W, Noh DY, Kim SW (2009) The accuracy of preoperative core biopsy in determining histologic grade, hormone receptors, and human epidermal growth factor receptor 2 status in invasive breast cancer. Am J Surg 197(2):266-269

45. Tamaki K, Sasano H, Ishida T, Miyashita M, Takeda M, Amari M, Tamaki N, Ohuchi N (2010) Comparison of core needle biopsy (CNB) and surgical specimens for accurate preoperative evaluation of ER, PgR and HER2 status of breast cancer patients. Cancer Sci 101(4):1051-1058

46. Arnedos M, Nerurkar A, Osin P, A'Hern R, Smith IE, Dowsett M (2009) Discordance between core needle biopsy (CNB) and excisional biopsy (EB) for estrogen receptor (ER), progesterone receptor $(\mathrm{PgR})$ and HER2 status in early breast cancer (EBC). Ann Oncol 20(12):1948-1952

47. Nguyen DX, Bos PD, Massague J (2009) Metastasis: from dissemination to organ-specific colonization. Nat Rev Cancer 9 (4):274-284

48. Cui X, Schiff R, Arpino G, Osborne CK, Lee AV (2005) Biology of progesterone receptor loss in breast cancer and its implications for endocrine therapy. J Clin Oncol 23(30):7721-7735

49. Brankovic-Magic M, Jankovic R, Neskovic-Konstantinovic Z, Nikolic-Vukosavljevic D (2002) Progesterone receptor status of breast cancer metastases. J Cancer Res Clin Oncol 128(1):55-60 